Article

\title{
Exploring the Driving Factors of the Spatiotemporal Variation of Precipitation in the Jing-Jin-Ji Urban Agglomeration from 2000 to 2015
}

\author{
Feili Wei ${ }^{1}$, Ze Liang ${ }^{1}{ }^{\oplus}$, Yueyao Wang ${ }^{1}{ }^{(}$, Zhibin Huang ${ }^{2}$, Huan Wang ${ }^{1}$, Fuyue Sun ${ }^{1}$ and \\ Shuangcheng $\mathrm{Li}^{1 \text {,* }}$ \\ 1 Key Laboratory for Earth Surface Processes of the Ministry of Education, College of Urban and \\ Environmental Sciences, Peking University, Beijing 100871, China; weifeili@pku.edu.cn (F.W.); \\ liangze@pku.edu.cn (Z.L.); wyywyy16@pku.edu.cn (Y.W.); 1906593362@pku.edu.cn (H.W.); \\ fuyuesun@pku.edu.cn (F.S.) \\ 2 The Organization Department of the Nanning Committee of the CPC, Nanning 530021, China; \\ hzbapple@163.com \\ * Correspondence: scli@urban.pku.edu.cn
}

Received: 15 August 2020; Accepted: 8 September 2020; Published: 10 September 2020

\begin{abstract}
Urbanization has a significant impact on urban precipitation. Existing studies on precipitation pay more attention to the impact of natural and meteorological factors, and the research on the impact of urbanization on the spatial patterns of precipitation is still very deficient. Based on geographic detection, this study quantitatively analyzed the dominant, interaction, and sensitivity factors that affect precipitation changes in more than 150 urban units in Jing-Jin-Ji (Beijing-Tianjin-Hebei) during the process of urbanization. The research findings show the following: (1) The dominant factors have seasonal differences in terms of the precipitation variation in Jing-Jin-Ji. The leading factors in summer were the change of radiation and relative humidity. The dominant factors in winter were the changes in radiation, relative humidity, and wind speed. On the annual scale, the dominant factors were the changes in relative humidity, aerosol optical depth, radiation, and wind speed. (2) Whether in summer, in winter, or on the annual scale, urbanization can enhance the explanatory power of spatial variation of urban precipitation through interaction with natural/meteorological factors, and all the dominant interaction factors show a nonlinear enhancement trend. (3) The night light intensity and urban heat island can greatly amplify the explanatory power of other factors, thus becoming the most sensitive factor in urbanization precipitation changes. The above research can provide a theoretical basis for the formulation of urban climate policies and urban planning.
\end{abstract}

Keywords: urbanization; precipitation; geographical detector; dominant factor; interacting factor

\section{Introduction}

Climate change has become an indisputable fact that has a significant impact on urban precipitation. In the context of global warming, urbanization leads to changes in the underlying surface, which has an important effect on the local climate [1-6].

Hitherto, a great number of studies have been carried out to investigate the impact of urbanization on precipitation. Most studies' findings suggest, to some extent, that UHI (urban heat island intensity, Table S1) contributes to precipitation in cities [7-10]. A similar phenomenon whereby UHI contributes to precipitation in cities was found in studies at both in China and abroad: in domestic cities, such as Beijing [11], Guangzhou [12,13], and Jinan [14], and in foreign cities, such as Tokyo [15], Singapore [16], Houston [17], Atlanta [18], Mumbai [19,20], and Berlin [21]. A precipitation increase along with the process of urbanization could be found mainly in the downwind region of the city during the warm 
season [22-25]. For example, research results showed that the precipitation would increase by up to $5-25 \%$ compared with the background values in the downwind region $20 \sim 50 \mathrm{~km}$ away from the city [22].

However, some studies' findings have shown that the UHI could reduce urban rainfall, especially in winter [10]. Furthermore, some scholars argue that the AOD (aerosol optical depth) can enhance or reduce precipitation in urban areas $[26,27]$. Some other scholars have carried out studies that state that the changes in the underlying surface of a city, such as an increase in impermeable area or an increase or decrease in vegetation, would affect the variation of latent heat and sensible heat in the city, and then affect the precipitation of a city [17]. Other scholars analyzed the influence of changes in surface hydrothermal conditions caused by urbanization on precipitation from the perspectives of surface albedo, frictional velocity, latent thermal heat, sensible heat, and so forth [28]. No matter which aspects and influencing factors we analyze, the impact of urbanization on precipitation can be traced from the changes in atmospheric thermodynamics, dynamic conditions, the composition of the urban environment, and so on. Some scholars attribute the impact of urbanization on precipitation to influencing mechanisms: the UHI effect [28-30], variations in the underlying surface [28,31,32], AOD emissions [26,27], and so on.

In different areas, however, the mechanisms are usually varied in their manifestation: they interact with each other and with regional geography and climate background factors. Currently, there has not yet been a final conclusion about which mechanisms dominate the precipitation process in urban areas, or how the different mechanisms interact with each other. In addition, most of studies are carried out to explore the influence of urbanization on precipitation, the connotations of urbanization are diverse and thus difficult to investigate in-depth for the characterization of a particular area.

However, in terms of research areas, the research mentioned above is usually based on statistics from the same city or cities at the same level. At present, during the rapid expansion of urbanization, there are relatively few statistical studies that have been carried out on whether the merging of cities, the differentiation of functional areas, and the spatial agglomeration of cities with different sizes have let to similar outcomes. Furthermore, most of the studies were conducted on the basis of the influence of a sole factor, and there are relatively few studies on the coupling effects between factors. There are few studies that assess whether there are mutual influences among different factors affecting the urban precipitation, and whether the influences are in a linear or non-linear form, as well as whether they are enhanced or weakened, and so forth. As for the methodology, the research methods employed are usually correlation analysis, such as partial correlation analysis and complex correlation analysis, and so on. The method to recognize the interaction between factors is usually to add the multiplication of two factors into the regression equation. However, the synergy of two factors does not always represent the multiplication relation. When two factors have other relationships between them, this method may cause some deviation between the research results and the actual situation [33]. While the factors that affect urban precipitation are intricate and complex, the influence of each factor is non-linear, non-stationary, and shows strong spatial heterogeneity [33]. Accordingly, based on the complex relationship between precipitation and urbanization, it is essential to evaluate the impact of urbanization on precipitation scientifically, accurately, and quantitatively. Urban agglomeration between cities, or inter-city coordinated development, would become an inevitable trend. Therefore, studies on the effect of urban agglomeration and urbanization on precipitation will have significance as references for future urban planning, the design of municipal traffic, and climate policy systems.

The geographical detector is mainly employed to analyze the effect of independent variable $X$ pattern on dependent variable $Y$ spatial pattern. Up to now, there have not been many studies based on this mentioned methodology to investigate the spatial distribution pattern for the variation of urban precipitation. The geographical detector method is based on the analysis of spatial variance. It can also be used to detect the real interaction effect between two variables. This method has been widely utilized in the fields of social sciences, natural sciences, public health, environmental sciences, and so on [34-40]. 
Based on the geographical detector method, the research data were selected from more than 150 urban research units in the Jing-Jin-Ji urban agglomeration from 2000 to 2015. This study aims to explore the relationship between urbanization impact factors and precipitation. The reason for taking the Jing-Jin-Ji urban agglomeration as the subject is that it has undergone a rapid urbanization process, so we hope to more easily detect the negative effects associated with rapid change. This urban agglomeration is one of the most densely populated regions in the world, so studying it may help prevent extreme weather events and improve human well-being. In addition, the urban agglomeration contains a large number of cities on different scales, so we can do research into the impact of urbanization on different scales of cities in terms of precipitation. Finally, the landscape of this urban agglomeration is dominated by plains, with little difference between the latitude and longitude, and the climatic background of each city is similar; hence, the effect of the regional climatic background can be ignored in this regard to some extent. In terms of exploring the relationship between the impact factors of precipitation of urbanization in urban agglomeration, this study aims to answer the following questions:

(1) What are the leading factors affecting the spatial and temporal changes of precipitation in the Jing-Jin-Ji urban agglomeration, and how important are the urbanization factors? (2) To what extent does urbanization exacerbate the impact of natural factors to change linear action to nonlinear action, and which factors have stronger interactions? (3) What are the sensitivity factors that cause changes in precipitation in Jing-Jin-Ji city?

\section{Materials and Methods}

\subsection{Study Area}

The Jing-Jin-Ji urban agglomeration is located at $113^{\circ} 27^{\prime} \mathrm{E}-119^{\circ} 50^{\prime} \mathrm{E}, 36^{\circ} 03^{\prime} \mathrm{N}-42^{\circ} 40^{\prime} \mathrm{N}$ (Figure 1), including Beijing, Tianjin, and Hebei province, with a total of 150 town units [41]. The Jing-Jin-Ji urban agglomeration is the center of politics, culture, and international communications in China, covering an area of $218,000 \mathrm{~km}^{2}$; the topography ranges from plains, terraces, and hills to mountain areas, but in general, the plains are dominant. The typical temperate monsoon climate features four distinct seasons: it is cold and dry in the winter, and hot and rainy in the summer. According to statistics for Jing-Jin-Ji in 2016, the permanent residents numbered 110 million, the economic aggregate amounted to 7461.26 billion RMB, and the per capital regional GDP (Gross Domestic Product) reached 68,000 RMB, which is 1.3 times the national average (2016 Statistics of Jing-Jin-Ji). From 2000 to 2015, the Jing-Jin-Ji region experienced rapid urbanization. According to the statistics of 150 cities and towns selected in this study, the urban area increased by $3526 \mathrm{~km}^{2}$ from 2000 to 2015 . Compared with the year 2000, the urban area increased by $110 \%$ in 2015 . The rapid expansion of urbanization exerted a considerable impact on the microclimate of the Jing-Jin-Ji urban agglomeration. Extreme precipitation events occurred frequently in recent years, causing great losses of money and property. The UHI and air pollution brought about by rapid urbanization go alongside global warming, which will ultimately have a major impact on the local climate. This will increase the probability of extreme precipitation events. The coordinated development of Jing-Jin-Ji could promote political stability, economic prosperity, and cultural development in China. What is more, Jing-Jin-Ji is one of the fastest growing areas of urbanization in China, so it can be used to predict the changes the rest of China will undergo in the future. To study the urbanization impact on precipitation and reveal the relationship between precipitation and impact factors could not only provide significant suggestions for flood control and drainage for each city in Jing-Jin-Ji, but also offer reference values for the development of other urban agglomerations in the future. 


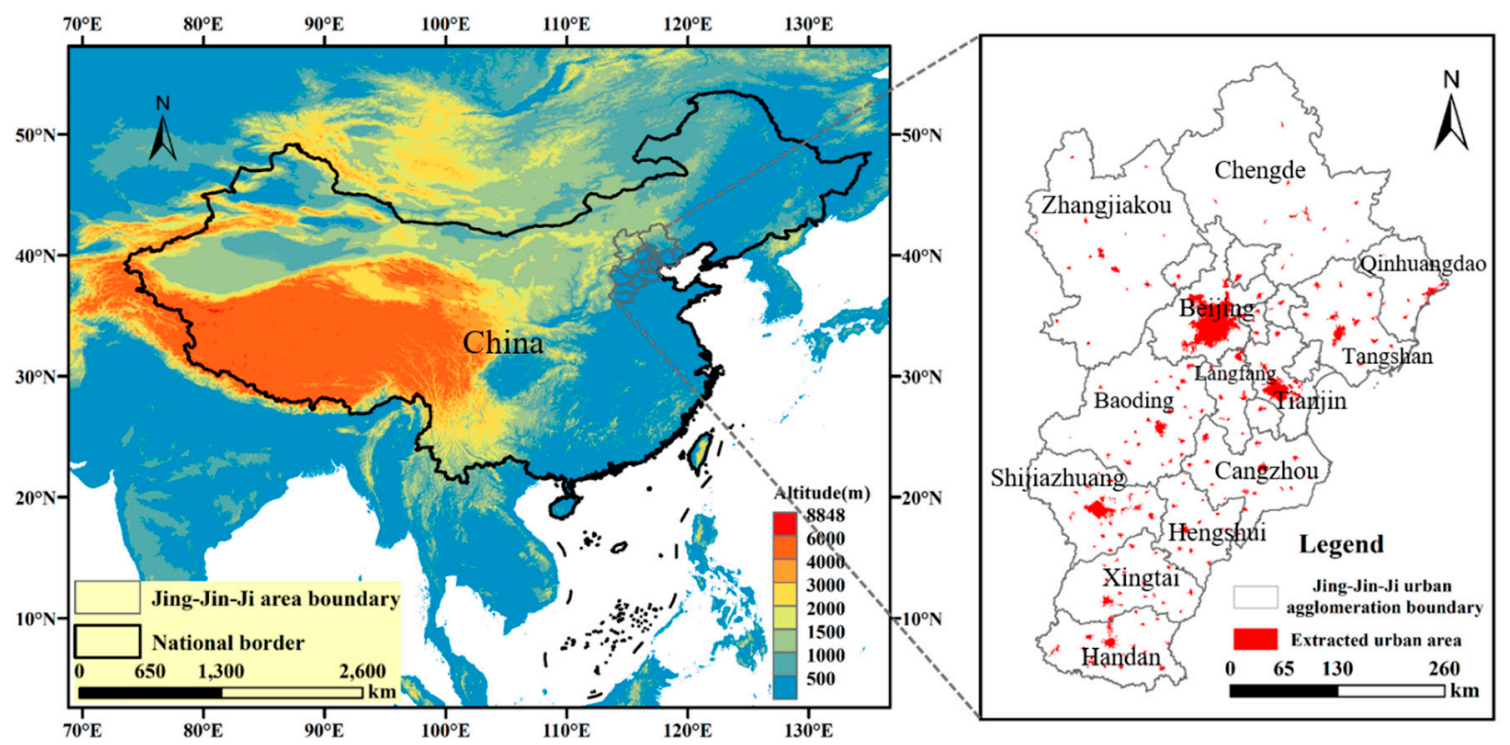

Figure 1. Location of the study in Jing-Jin-Ji.

\subsection{Data Sources}

\subsubsection{Variable Selection}

This study selected AREA (urban AREA) and POP (population density per unit area in urban area) to represent the level of urbanization; AOD, NLI (night light intensity value), and UHI stand for artificial factors in the process of urbanization; NDVI (normalized difference vegetation index), RAD (solar radiation), RHU (relative humidity), and WIN (wind speed) represent the weather/natural factors. The selection is based on the following:

AOD provides condensation nuclei for precipitation; both the concentration degree and the size of AOD affect the starting time of rainfall and the amount of precipitation [26]. The variations of the city's underlying surface, such as AREA [42,43] and NDVI [44,45], are important to the heat and moisture balance; the bigger the constructing area, the more the impervious area. The more the soil moisture evaporation is restrained, the greater the sensible heat flux, and the less the latent heat flux. All these factors would be of vital importance to the stability of the city's UHI and atmosphere. NDVI represents the growth of vegetation; the transpiration of vegetation has a significant impact on atmospheric RHU and the variations in surface temperature. NLI stands for the intensity of human activities [46]. The higher the NLI value, the greater the effect of the surface modification. The bigger the POP density per unit area, the more anthropocentric heat is emitted from transportation and other emissions [47]. All these factors affect the urban thermal balance. Under appropriate conditions, the greater the RHU, the greater the chance of precipitation. Wind affects the diffusion of the water vapor cycle, pollutants, and the heat dissipation of the city. UHI affects the stability of the near-stratigraphic atmosphere of the city [29]. The larger the UHI, the more unstable the near-stratigraphic atmosphere, which could easily trigger convective precipitation. Research findings argue that precipitation over the city and in the downwind direction is higher than in other surrounding areas.

The factors mentioned above mainly include the influence of natural and socioeconomic factors. The trends for each factor in the process of urbanization between 2000 and 2015 are shown in Figure S1.

\subsubsection{Data Source}

The data on variations in land utilization from 2000 to 2015 were drawn from the Resource and Environmental Data Cloud platform of the Institute of Geographic Sciences and Resources Research, Chinese Academy of Sciences (http://www.resdc.cn/), for which the spatial resolution was $30 \mathrm{~m}$. The urban area was calculated by using the area occupied with urban patches in each 
phase's data of the land utilization. The data for AOD were obtained from remote sensing products (MOD04C6), for which the spatial resolution was $10 \mathrm{~km}$. The data of NDVI were drawn from the products' data of the monthly and annual synthesis normalized difference vegetation index (https://lpdaac.usgs.gov/dataset_discovery/modis/modis_products_table/mod13a3_v006), for which the resolution was $1 \mathrm{~km}$. The NLI is the mean value of the NLI on the patches of each town, which comes from Li et al. [46]. The POP within the urban patch area is obtained by counting the population density of each urban and town unit based on the data from the NASA Socioeconomic Data Center (http://sedac.ciesin.columbia.edu/data/set/gpw-v4-population-density-rev10). The meteorological data, such as precipitation, air relative humidity, average WIN, and so on, were collected from the historical monitoring data of the National Meteorological Center of China (http://data.cma.cn), while the spatial grid was obtained via ordinary Kriging interpolation. A further step was to obtain re-samples according to the boundary of each phase of urban units.

This study employed remote sensing inversion products to obtain data on the surface temperature from the geographical spatial data (http://www.gscloud.cn/) on land surface temperature synthetic products (MODLT1T), for which the spatial resolution was $1 \mathrm{~km}$. Meanwhile, the data were arranged according to the annual synthetic surface temperature of the product in the summer and winter of 2000, 2005, 2010, and 2015, and then the surface temperature of Jing-Jin-Ji from 2000 to 2015 was obtained accordingly. Monthly and annual synthetic surface temperatures were utilized to calculate UHI in different seasons. The difference in surface temperature in the suburbs is used to represent the intensity of UHI. Due to the expansion of Jing-Jin-Ji from 2000 to 2015, and in order to ensure equal attention to urban and suburban areas within the time range covered, the intensity of the UHI effect in this study is comparable in different years and seasons. This study is based on the average surface temperature of the patch in the urban boundary in 2000 to stand for the urban land surface temperature (LST). Meanwhile, on the basis of the buffer with a width of $10 \mathrm{~km}$ [41] established around the city in 2015, the LST in suburban areas is obtained by calculating the average surface temperature. The surface UHI intensity is calculated via Equation (1):

$$
\mathrm{UHI}=L S T(\text { urban })-L S T(\text { suburban }) .
$$

\subsection{Methodology}

\subsubsection{Linear Regression Analysis}

This study makes use of linear regression analysis to calculate the changing situation of AOD, AREA, NDVI, NLI, POP, RAD, RHU, UHI, and WIN in summer and winter in 2000-2015, and the change slope of each factor from 2000 to 2015 was obtained (Figure S2).

The slope of precipitation change from 2000 to 2015 is the dependent variable. The slopes of seasonal change of AOD, AREA, NDVI, NLI, POP, RAD, RHU, UHI, and WIN were used as input independent variables so as to calculate the impact of various factors on summer and winter as well as annual precipitation change rates in different cities of Jing-Jin-Ji.

\subsubsection{Geographic Detector}

Geographic detector is used as a statistical method utilized to carry out research on the influencing factors and mechanism of spatial stratified heterogeneity. Spatial stratified heterogeneity refers to the phenomenon of the sum of the variances within layers being less than the total regional variance.

The core concept of the method is that, if an independent variable has an important impact on the dependent variable, the spatial distribution between the independent and the dependent variable is consistent. A geographical detector contains four modules: factor, interaction, risk, and ecological detectors [33]. This study mainly used the factor detector and interaction module.

A factor detector is mainly employed to detect the spatial stratification heterogeneity of the variation in precipitation and the degree of interpretation for the spatial differentiation of precipitation 
change caused by different factors in cities of Jing-Jin-Ji. The explanatory power is assessed by the $q$ value; the calculation principle is based on analysis of variance, as expressed by the following equation:

$$
q=1-\frac{\sum_{h=1}^{L} N_{h} \sigma_{h}^{2}}{N \sigma^{2}}=1-\frac{S S W}{S S T},
$$

where

$$
S S W=\sum_{h=1}^{L} N_{h} \sigma_{h^{\prime}}^{2} S S T=N \sigma^{2} .
$$

In Equations (2) and (3), $h=1,2 \ldots L$ is the stratification of independent variable $X ; N_{h}$ and $N$ are the number of units within layer $H$ and the region; $\sigma_{h}^{2}$ and $\sigma^{2}$ are the variance of the stratification of $H$ and the variance of the dependent variable $Y$, respectively; and SST is the total variance of the region.

The range of $q$ is $[0,1]$. A greater $q$ value indicates stronger spatial stratification and heterogeneity of variable $Y$, which would make the interpretation power of independent variable $X$ to variable $Y$ stronger. According to the $q$ value size, the effect of independent variables on dependent variables can be detected, and the leading factors in precipitation change in different cities of Jing-Jin-Ji can be assessed intuitively. The software of the geographic detector will test the significance while generating a $q$ value.

The interaction detector can be used to detect the impact of interaction between a pair of impact factors on precipitation. The mode and direction of interaction can be judged by comparing the $q$ value of a single factor and the $q$ value of their interaction. The interaction criteria are shown in Table 1.

Table 1. Types of interactions between two impact factors of precipitation changes.

\begin{tabular}{cc}
\hline Scenario & Interaction Types \\
\hline$q\left(X_{1} \cap X_{2}\right)<\operatorname{Min}\left(q\left(X_{1}\right), q\left(X_{2}\right)\right)$ & Nonlinear attenuation \\
$\operatorname{Min}\left(q\left(X_{1}\right), q\left(X_{2}\right)\right)<q\left(X_{1} \cap X_{2}\right)<\operatorname{Max}\left(q\left(X_{1}\right), q\left(X_{2}\right)\right)$ & Single factor nonlinear attenuation \\
$q\left(X_{1} \cap X_{2}\right)>\operatorname{Max}\left(q\left(X_{1}\right), q\left(X_{2}\right)\right)$ & Double factor enhancement \\
$q\left(X_{1} \cap X_{2}\right)=q\left(X_{1}\right)+q\left(X_{2}\right)$ & Independence \\
$q\left(X_{1} \cap X_{2}\right)>q\left(X_{1}\right)+q\left(X_{2}\right)$ & Nonlinear enhancement \\
\hline
\end{tabular}

The geographic detector requires input variables as the categorical variables, which means that continuous data need discretization processing. The natural break point method reduces the difference at the same hierarchy, increasing the size of different hierarchical differences in terms of the natural clustering method. The natural clustering method narrows the average layer in discrete minimum variance and maximizes the average discrete maximum variance. The natural clustering method is widely used in the classification of variables for a geographical detector. Therefore, this study adopts the natural break point method to categorize the data. We divided the continuous data of each factor into nine categories. The consistent stratification method was applied for each influence factor in different seasons in order to ensure that the effect of the impact factor on the change of precipitation was explored under the same stratification conditions, which guarantees the comparability of results.

\section{Results and Analysis}

\subsection{The Spatial Variation of Urban Precipitation in Different Seasons in Cities of Jing-Jin-Ji}

As can be seen from Figure 2, the annual precipitation showed a decreasing trend in the Jing-Jin-Ji urban agglomeration from 2000 to 2015 (Figure 2a). The significant decrease in annual precipitation was mainly located in the southern region, while there was a relatively small decrease in the northern region, which shows a trend of gradual decrease from south to north. From the cold-hot spot analysis diagram (Figure S1a), the trend of accumulation precipitation decrease has no significant variation 
in the towns of Handan, Hengshui, and Cangzhou of the Jing-Jin-Ji urban agglomeration, and two centers are formed when taking the towns of these three areas as a boundary: Beijing is regarded as the center in the north where the precipitation is decreasing, while the city of Handan is taken as the center in the south where the precipitation is become decreasing (Figure 1). Both two centers have passed the significance test of $99 \%$. In summer, the increase in precipitation was mainly concentrated in the larger urban area of Beijing, the small towns in the northeast of Qinhuangdao, and some small towns in the south of Handan City. The decrease in cumulative precipitation was mainly distributed in the towns around Shijiazhuang and Hengshui of Hebei province (Figure 2b). From the analysis of cold-hot spots of precipitation change from 2000 to 2015, it can be seen that regions with decreased and slightly increased precipitation all passed the significance test of $99 \%$ (Figure S1b), while other regions do not show significant changes. In winter, the slight increase in precipitation was mainly distributed in urban areas of Beijing as well as in the cities and towns of Baoding and Shijiazhuang. The precipitation showed a decreasing trend in the northeast of Tangshan, in the cities and towns of Qinhuangdao and Xingtai as well as in the south of Handan (Figure 2c). From the analysis of cold-hot spots, according to the precipitation increase or decrease in the cities and towns located in the Jing-Jin-Ji urban agglomeration in winter, three regional zones can be created to show the amount of precipitation: the decreasing zones refer to the northeast and the south, and the increasing zone was Beijing-Baoding-Shijiazhuang (Figure S1c).
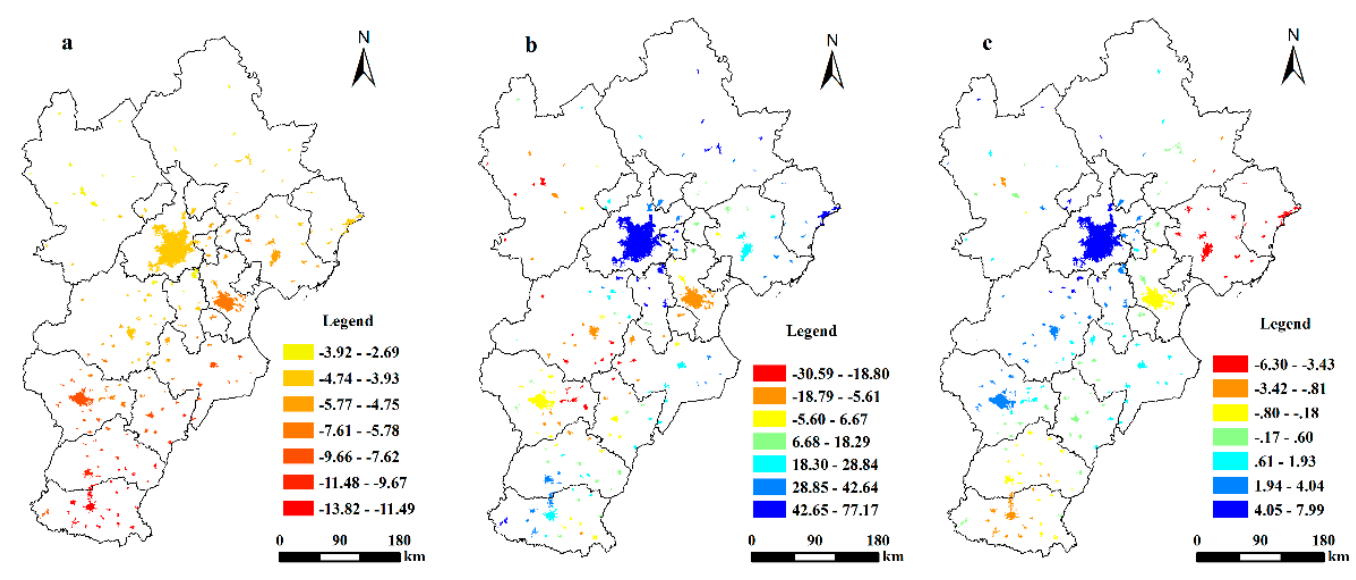

Figure 2. Spatial variation of precipitation in Jing-Jin-Ji from 2000 to 2015: (a) annual variation; (b) in the summer; (c) in winter.

\subsection{Geographical Detection of Dominant Factors Affecting Annual Precipitation Variation in Different Seasons}

\subsubsection{Detection of Impact Factors for Urban Precipitation Variation in Different Seasons}

The explanatory power of the impact factors of urban precipitation variation in different seasons is mainly determined by the $q$ value. The larger the $q$ value, the stronger the spatial stratification and heterogeneity of precipitation variation, and the stronger the explanatory power of the respective variables on precipitation change. The leading factors of precipitation variation in different cities and towns in Jing-Jin-Ji urban agglomeration could be intuitively assessed according to the size of the $q$ value. The results of the factor detector show that there is no significant difference for the leading factors of precipitation variation in different seasons in Jing-Jin-Ji (Figure 3, Table 2).

In summer, the change of RAD has become the most important impact factor for precipitation variation, which would explain $21.3 \%$ of the spatial distribution of precipitation variation. Then, the change of RHU comes after RAD, which can explain $16.9 \%$ of the spatial distribution of precipitation variation. The changes of RAD and RHU passed the 99\% significance level. Except for RAD and RHU, the $q$ value of the other factors is small, and their explanatory power is less than $10 \%$; in particular, the explanatory power of NLI and POP is under $5 \%$, which demonstrates that the change in human 
activities does not directly influence urban rainfall change in comparison with meteorological factors. In general, the change in each factor has little influence on the change of precipitation in cities of Jing-Jin-Ji. In winter, the dominant factors include RAD, RHU, WIN, and AREA. The explanatory power of RAD variation reached $43.3 \%$, ranking first, then comes the change of RHU with an explanatory power of $41.9 \%$. The third and fourth places go to WIN and AREA, with the explanatory power reaching $18.0 \%$ and $11.5 \%$, respectively. Among them, RAD, RHU, and WIN passed the significance test of $99 \%$ and the significance test of $90 \%$ for AREA. The human factors such as NLI and UHI, together with NDVI caused by urbanization, have little impact on precipitation change. From the annual scale, we see that the main impact factors of precipitation change include the variation of RHU, AOD, RAD, and WIN. RHU has the highest explanatory power (33.2\%), then AOD (30.0\%), and then $19.9 \%$ and $14.6 \%$ for RAD and WIN, respectively.

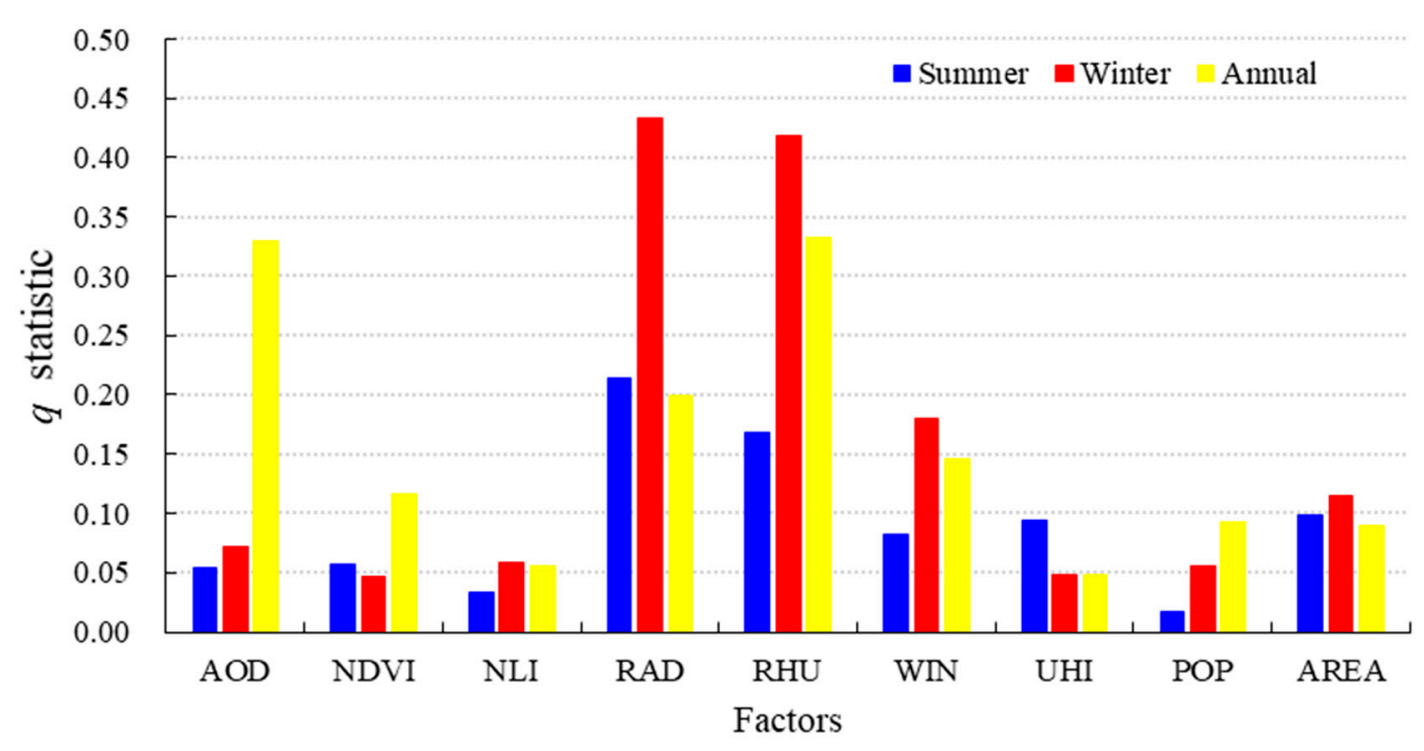

Figure 3. Importance ranking of impact factors of precipitation change in Jing-Jin-Ji from 2000 to 2015.

Table 2. The $q$ value statistics of different impact factors on urban precipitation change in Jing-Jin-Ji from 2000 to 2015.

\begin{tabular}{cccc}
\hline Factors & Summer & Winter & Annual \\
\hline AOD & 0.055 & 0.072 & $0.330^{* * *}$ \\
NDVI & 0.057 & 0.047 & 0.116 \\
NLI & 0.034 & 0.058 & 0.055 \\
RAD & $0.213^{* * *}$ & $0.433^{* * *}$ & $0.199^{* * *}$ \\
RHU & $0.169^{* * *}$ & $0.419^{* * *}$ & $0.332^{* * *}$ \\
WIN & 0.082 & $0.180^{* * *}$ & $0.146^{* *}$ \\
UHI & 0.094 & 0.049 & 0.048 \\
POP & 0.017 & 0.055 & 0.093 \\
AREA & 0.099 & $0.115^{*}$ & 0.090 \\
\hline$* * *$ standing for $p<0.01 ; * *$ for $p<0.05 ;{ }^{*}$ for $p<0.1$.
\end{tabular}

It can be easily seen that the change in AOD has little impact on precipitation in summer and winter, but a large impact on the annual scale. The reason may be that the change in AOD has no direct impact on precipitation change but could be indirectly reflected in the interaction with other factors (Table 3). It should be noted that we did not consider the impact of AOD on precipitation changes in spring and autumn. Whether in summer or in winter, urbanization factors (especially the change in area) had a direct effect, but the change in AREA had a greater impact on the variation of precipitation, which ranked third in the summer, with an explanatory power of $9.9 \%$; its ranking was fourth in winter, slightly lower than the change of WIN, whose explanatory power was $11.5 \%$. During the 
process of urbanization, the scale of a city has a significant impact on the urban rainfall; therefore, extreme drought and flooding must be prevented, and the size of the city needs to be controlled to a certain extent. By comparing the precipitation of the whole year and that in winter, the change of $\mathrm{UHI}$ in summer has a great impact on the change in precipitation. In short, changes in natural factors, such as RHU, RAD, and WIN, have a big impact on precipitation changes on both a seasonal and an annual scale in Jing-Jin-Ji.

Table 3. The interaction $q$ values of the influencing factors of precipitation in different cities in the Jing-Jin-Ji from 2000 to 2015.

\begin{tabular}{|c|c|c|c|}
\hline & Summer & Winter & Annual \\
\hline Interaction 1 & RAD NDVI & RHUnAOD & RHUnRAD \\
\hline$q$ value & 0.646 & 0.766 & 0.74 \\
\hline Interaction 2 & UHInRHU & 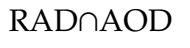 & $\mathrm{RAD} \cap A O D$ \\
\hline$q$ value & 0.564 & 0.733 & 0.694 \\
\hline Interaction 3 & 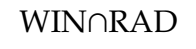 & 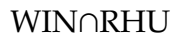 & $A R E A \cap R H U$ \\
\hline$q$ value & 0.558 & 0.729 & 0.661 \\
\hline Interaction 4 & 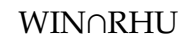 & RHUnRAD & RHUnAOD \\
\hline$q$ value & 0.546 & 0.722 & 0.639 \\
\hline Interaction 5 & UHInNLI & 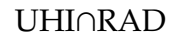 & $\mathrm{UHI} \cap \mathrm{AOD}$ \\
\hline$q$ value & 0.54 & 0.713 & 0.638 \\
\hline Interaction 6 & UHInRAD & 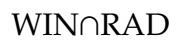 & NDVI AOD \\
\hline$q$ value & 0.537 & 0.711 & 0.634 \\
\hline
\end{tabular}

\subsubsection{Detection of the Dominant Interaction Factors of Urban Precipitation in Different Seasons}

The interaction detector can be used to detect the impact of interaction in pairs among impact factors on precipitation change. By comparing the $q$ value of a single factor and the interaction $q$ value, the mode and direction of interaction can be assessed accordingly. Three types of interaction results could be obtained for summer, winter, and the year after analysis (Tables S2-S4). The detection results of the three types of interaction show that the $q$ value after two factors' interaction is greater than that of a single factor, which indicates that the interaction of the two factors would enhance the explanatory power of precipitation change. The leading interaction of precipitation changes differs for different seasons.

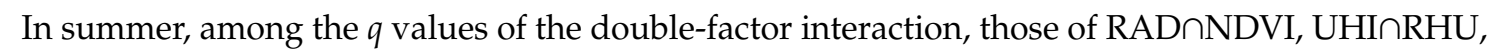

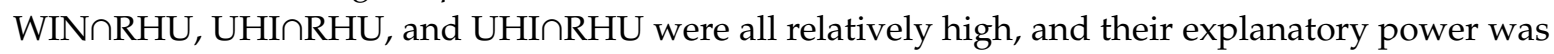
above $50 \%$ (Table 3), which indicates that a combination of these factors would become the leading factor affecting the precipitation changes in summer for different cities in Jing-Jin-Ji. No matter the change of factor or the interaction with other factors, the $q$ value of RAD is fairly large, which indicates that the urbanization process of Jing-Jin-Ji has a crucial influence on the change of precipitation. In addition, changes in natural factors, such as the of WIN and RHU, together with other factors, magnify their own variation for the impact on the variance of precipitation. This suggests that the transformation of the earth's surface changes WIN and RHU during the process of urbanization, which produces a significant influence on the precipitation variation of Jing-Jin-Ji. As can be seen from Tables 2 and 3, the change of NDVI exerts little impact on the change of urban rainfall; however, after it is combined with the changes of RAD, the interaction $q$ value increased significantly with an explanatory power of up to $64.6 \%$, ranking first among all the interaction factors. This indicates that the NDVI has little effect on the change in precipitation before their combination. The change in a single factor, UHI, had little direct influence on precipitation, but its explanatory power could reach up to $56.4 \%$ by combining with the change of RHU. The interaction $q$ value is far greater than the respective $q$ values when UHI is combined with NLI with an explanatory power of $54 \%$. This suggests that, in the process of urbanization, the increase in human activities contributes to the sharp change of UHI; thus, a further effect would bring about precipitation changes along with the urbanization. 
Human activities did not directly affect the precipitation change; however, they have a significant impact on precipitation change in terms of changing the natural factors. It can be seen that the impact of the interactions among these factors on precipitation change is nonlinearly enhanced by $q(x 1 \cap x 2)>$ $q(x 1)+q(x 2)$.

In winter, except for the fact that the combined $q$ values of RAD and RHU were greater than $\operatorname{Max}(q(\mathrm{RAD})$ and $q(\mathrm{RHU}))$, which presented a two-factor enhancement, the interaction $q$ value of other factors was greater than the sum of the $q$ values of the single factors, namely $q(x 1 \cap x 2)>q(x 1)$ $+q(x 2)$, which presents a nonlinear enhancement trend. The combination of natural factors such as RAD, RHU, and WIN interacts with other factors that are the leading factors affecting precipitation change. Among all the interaction factors, the $q$ values of interaction factors are relatively higher than

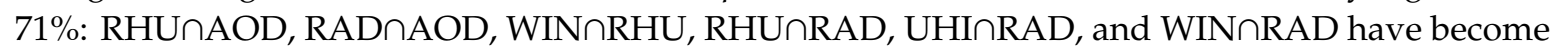
the leading interaction factors influencing the precipitation change in winter in Jing-Jin-Ji (Table 3). Although the single factor variations of AOD and UHI (Table 2) had little effect on the change in precipitation, when they were combined with RAD and RHU, the interaction of the $q$ value increased significantly, and the explanatory power was greatly increased, surpassing the combination of other factors. This shows that the change in urban rainfall in winter to some degree has a relationship with the pollutants emitted by human activities. Although urban area plays a certain role as a single factor, when combined with other factors, even if the $q$ value is increasing, the explanatory power is not very prominent. This indicates that, on the whole, the change of area does not have a significant effect on the change in precipitation in Jing-Jin-Ji during urbanization.

It can be seen from Table 3 that, all through the year, after all the factors have interacted with each other, their $q$ values are greater than their individual ones, except the $q$ value of RHUnAOD is in between of the sum $q$ value of RHU and AOD, presenting double-factor enhancement. The $q$ value of other interaction factors is far greater than that of the two combined factors that are presenting nonlinear

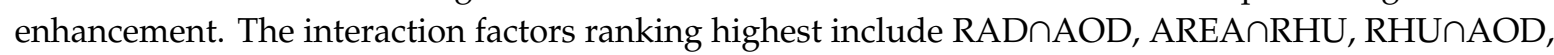

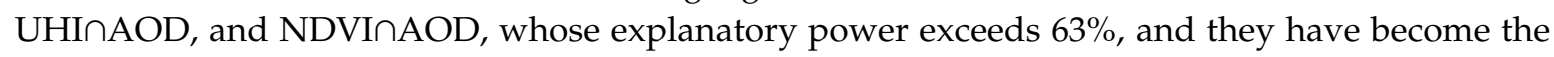
leading interaction factors for precipitation change in Jing-Jin-Ji (Table 3). It is not difficult to see from Table 3 the combination effect of RHU and RAD, with an explanatory power up to $74 \%$, which is first place among all interaction factors. RHU and RAD have also become the most important interaction factors that affect the urban precipitation change in Jing-Jin-Ji. This shows that, during the process of urbanization, the combined effects of changes in natural/meteorological factors have become the most significant factor affecting the change of urban rainfall in Jing-Jin-Ji. These research findings are consistent with the leading factor of precipitation change in summer and winter. Their own influences will be further amplified when RHU and RAD are combined with AOD, which is consistent with the changing trend of precipitation in winter. The influence of area change on precipitation variation is not significant in summer or winter, but its influence is multiplied throughout the year through combination with RHU. This indicates that as the impervious area of the city increases, the sensible heat flux increases, while the latent heat flux decreases. This also increases the intensity of UHI to some extent.

\subsubsection{Sensitivity Analysis of Different Factors Affecting Precipitation Change in Different Seasons}

In order to detect the sensitivity of urban rainfall change to various factors in different seasons in Jing-Jin-Ji, we constructed a model to assess the sensitivity of the factors. If the $q$ value of two factors' interaction minus the $q$ value of a single factor, then accumulating the $q$ value obtained, when the $q$ value of the accumulation is greater than the $q$ value of the others, the interaction effect is more sensitive to precipitation change. It could be categorized as a sensitive factor. The results of the sensitivity analysis are in Figure 4 and Tables S5-S7. 

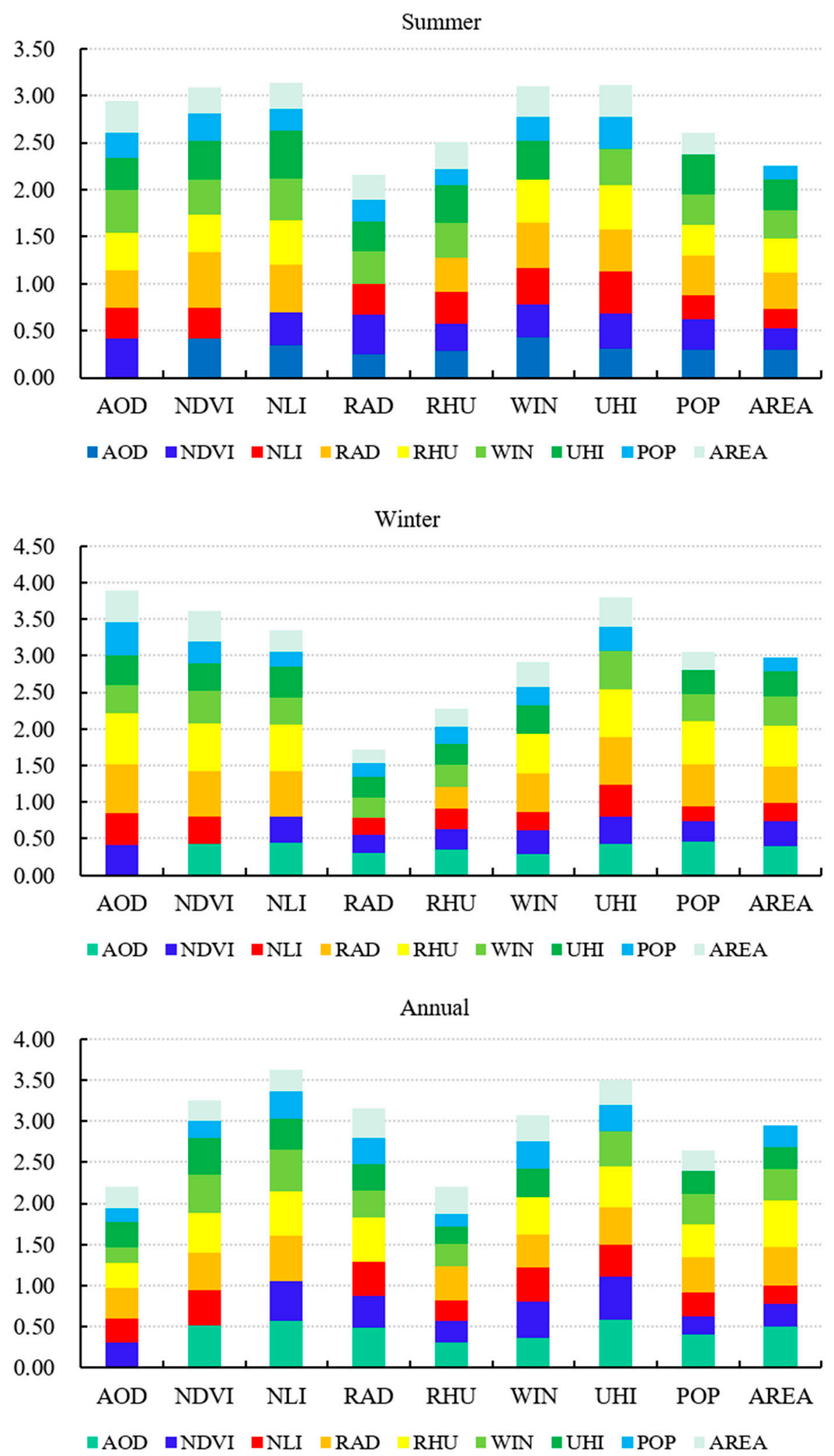

Figure 4. Cumulative changes in $q$ values for single factors and interaction factors (abscissa represents the factor that interacts with this factor, and ordinate represents the change of $q$ value of other factors after interaction with this factor). 
The data in Figure 4 show the results of the sensitivity analysis. In Figure 4 , the $q$ value of a single factor such as RAD and RHU is larger, which has become the main factor in the precipitation change; however, when interacting with other factors, the cumulative $q$ value of each factor has not changed much, which indicates that the sensitivity of factors like RAD and RHU is relatively stable. Although RAD and RHU are factors with high significance, they are not the most important sensitivity impact factors. It can be easily seen from the data shown in Figure 4 and Tables S4-S6 that, though the $q$ values of NLI and UHI are relatively small in different seasons, the cumulative variation of the sensitivity $q$ values for other factors are the highest after interaction when combining with other factors, no matter whether in summer, winter, or for the whole year. For example, in summer, after combination with NLI, the explanatory power of sensitivity $q$ values such as UHI, RAD, RHU, and WIN increased by $50.7 \%, 50.2 \%, 47.4 \%$, and $44 \%$, respectively. After combination with UHI, the sensitivity $q$ values of RAD and RHU increased by $44.3 \%$ and $47 \%$, and the sensitivity $q$ values of other factors also exceeded $30 \%$. This indicates that the interaction of NLI and UHI with natural/meteorological factors could enhance the influence of these factors and become the most sensitive factors influencing precipitation change in Jing-Jin-Ji. In summer, besides NLI and UHI, other factors were combined with NDVI, WIN, and AOD, and their cumulative $q$ values were also relatively large, which indicated that changes in vegetation cover and land surface properties had an impact on local atmospheric circulation and evapotranspiration, and thus an important impact on precipitation. In winter, after AOD and UHI interacted with other factors, the cumulative change of $q$ value of other factors was the largest, indicating that $\mathrm{AOD}$ and $\mathrm{UHI}$ in winter were the sensitivity factors affecting precipitation change in Jing-Jin-Ji. However, for the whole year, although the $q$ value of AOD changed greatly after interaction (Figure 3), its sensitivity to the excitation of other factors was not significant. Throughout the year, the sensitivity of AOD and RHU was the smallest, while the sensitivity of NLI and UHI was the biggest. Whether in summer or winter, or for the whole year, the areas on each factor change sensitivity performance is at the below-middle of the average. Figure 4 demonstrates that the sensitivity of the area was manifested in different seasons and by RHU interacting with RAD. During the winter, the area also interacts with AOD, which enlarges the influence of their interaction; however, the area of change in different seasons is relatively stable.

\section{Discussion}

\subsection{The Driving Factors of the Changes in Spatiotemporal Patterns}

For most cities of Jing-Jin-Ji, the results showed a significant reduction from 2000 to 2015, which has a significant spatial agglomeration phenomenon in terms of the analysis of cold-hot spots. Natural/meteorological factors, such as RHU, RAD, WIN, and NDVI, and human factors, such as UHI and NLI, exert impacts on urban rainfall, which is consistent with the findings of some researchers at home and abroad [48-51]. In other words, urbanization could affect precipitation by changing the city's natural/meteorological factors and human activities. Accordingly, the urbanization of a certain area has an important impact on the precipitation in that region.

Jiang et al. [49] conducted a statistical study on the Jing-Jin-Ji urban agglomeration. Their findings showed that the urbanization of the area resulted in a decreasing trend of annual precipitation, which is consistent with the research results of this paper. Based on a WRF model simulation, Wang et al. [50] found that urbanization in Beijing reduced precipitation in the urban area, by comparison with background values, by $11 \%$. This study concluded that urbanization would make the impermeable layer area increase and inhibit the surface evapotranspiration. The upward moisture obtained from soil and vegetation, the RHU, and the local precipitation moisture cycle were reduced accordingly. The research findings of this study are consistent with the change in RHU, which is one of the leading factors causing the change in precipitation in Jing-Jin-Ji. However, in the study by Jiang et al. [49], the overall situation of urban agglomeration, in terms of the statistical analysis, did not find temporal changes in the spatial units of each town. Based on a model simulation, Wang et al. [50] analyzed 
precipitation changes based on each single factor, assessing in detail the main factors of urbanization causing precipitation change without considering the interaction between factors; some factors do not directly affect the precipitation, but have a greater impact in combination with other factors.

Differently from the previous studies mentioned, the attribution analysis of spatial-scale precipitation change based on the geographic detector method focuses on the quantitative attribution of the spatial distribution of urban precipitation change; afterwards, a quantitative analysis is conducted on the influence of interactions among factors. According to the results of this study, the changes in RAD and RHU for single factors were the main factors affecting the changes in precipitation between seasons and years. Changes in RAD and RHU further increased the influence of natural factors on precipitation changes. The changes in RAD and RHU were all related to the albedo and Bowen ratios of the underlying surface. For example, in Table 2, although the spatial heterogeneity of NDVI is not significant on a single factor, the changes in the combination of RAD had a nonlinear enhancement effect on the precipitation variation in Jing-Jin-Ji. This indicates that, during the process of urbanization, the change in the underlying surface caused by human activities will intensify the changes in urban precipitation to a certain extent. In addition, on the annual scale, the combination of UHI and AOD enhanced the change in precipitation in urban areas. Urbanization intensifies the UHI, and the low-level updrafts caused by the UHI lead to the formation of low-level clouds, which then form deep convective clouds downwind of the urban area. Under a high concentration of AOD, the starting time of precipitation formed by the underlying cloud would be delayed [27]. Accordingly, it may develop downwind deep convective clouds and provide the right conditions for extreme precipitation. Consequently, the rainfall is decreasing in the inner urban area, but increasing in the downwind area. It should be noted that our statistics here are for the inner urban areas in 2000. Therefore, although the precipitation in the downwind direction increased, the precipitation in the inner urban areas may decrease in most cities. An extreme precipitation event that occurred downwind of Beijing in 2012 has been proven to be related to UHI enhancement [11]. It can also be seen from Table 3 that, on seasonal and annual scales, UHI could enhance the explanatory power of urban precipitation changes by acting with RHU, RAD, NLI, AOD, and so forth.

\subsection{The Impact of the Interaction of Human Factors and Natural Conditions on Precipitation in the Process of Urbanization}

From the analysis of sensitivity factors in Section 3.2.3, it can be seen that the sensitivity of human factors is getting stronger. The changes in natural factors such as RHU and RAD are the most important factors to affect precipitation changes; however, they are not the most sensitive factors affecting precipitation changes in Jing-Jin-Ji. Human factors such as UHI and NLI have a slight direct effect when interacting with RHU, RAD, WIN, etc.; the impact of these factors themselves has been greatly amplified, such that they have become the most sensitive factors.

A great many studies have shown that the presence of UHI increases atmospheric instability, which promotes the transport of water vapor from the ocean to the mainland $[16,19,25]$. Therefore, UHI can contribute to precipitation to a certain extent, especially in coastal areas $[7,20,30,52,53]$ such as Singapore [16], Tokyo [28], Manila [54], and Malaysia [55]. However, far from the sea or in an area with lower RHU, the condensation temperature of atmospheric water vapor is higher when influenced by UHI. It is not easy for water vapor to condense into clouds to rain; therefore, the starting time of precipitation is delayed in cities, which is likely to bring about more precipitation in downwind areas [22], while the precipitation over the city decreases instead. The urbanization level is higher in Jing-Jin-Ji, which has a larger impervious surface area and a lower air RHU. It can be seen in Figure S2j-l and Figure 2 that UHI mainly has an inverse correlation with precipitation change in different districts of Jing-Jin-Ji, which is different from the results for coastal areas in studies conducted by Oliveros et al. [54] and Ooi et al. [55], but brings the results into correspondence with the findings of Zhang et al. [45] and Wang et al. [50], which indicates that UHI may delay precipitation, leading to a decrease in precipitation in the city center. 
NLI represents the intensity of human activities [46]. The higher the NLI value, the stronger the human modification activities, and the more waste gas and heat will be emitted. Hence, the impervious area will increase accordingly. This will not only enhance UHI, but also bring about an impact on NDVI [45], etc. Those would affect the surface latent heat, sensible heat, surface flux, and water-heat balance. The research findings mentioned above suggest that, during the process of urban development, in order to prevent extreme droughts and flooding in cities, attention should be paid to the mitigation of UHI. In the process of land surface reconstruction, attention should also be paid to vegetation protection. Furthermore, AOD showed greater sensitivity in summer and winter. Studies have shown that the increase in AOD concentration makes water vapor more homogeneous to a certain extent, which reduces the efficiency of water droplets' collisions, and thus the probability of light rain is reduced accordingly. Moreover, AOD absorbs water vapor above the atmosphere when its concentration increases. Therefore, AOD has the effect of heating the atmosphere, meaning less of the RAD reaches the ground, which leads to a reduced temperature difference between the ground and the upper atmosphere. The outcome is that the atmosphere becomes more stable, which reduces the incidence of light rain, but it can provide better conditions for heavy rain [26,27]. Therefore, during the process of urbanization, in order to prevent extreme precipitation events, pollution emissions should be reduced as far as possible. The location of the city would play a certain role. However, after the combination with other factors, the $q$ value of the interaction factor increased, though the explanatory power was not very prominent in this regard, and the sensitivity of the $q$ value of other factors' combination has not yet increased significantly. These results show that, on the whole, during the process of urbanization, the change in area did not have a significant effect on the change in precipitation in Jing-Jin-Ji, but the effect of area on RHU was apparently amplified. The area and impermeable water surface increased, while the vegetation was less than previously [10]. The soil evaporation, transpiration of plants, and latent heat in the atmosphere all decreased, while the sensible heat increased. These phenomena would probably create ideal conditions for extreme precipitation events [56]. Therefore, in the process of urban development, attention should be paid to the protection of green space and afforestation.

\section{Conclusions}

This study was carried out by assessing the changes in nine factors, AOD, NDVI, NLI, RAD, RHU, WIN, UHI, POP, and AREA, in more than 150 towns of Jing-Jin-Ji in 2000-2015. Based on the geographical detector method, we analyzed the leading impact factors of the change in urban precipitation in Jing-Jin-Ji from 2000 to 2015 and the degree of interacting impact among the factors; then, conclusions were drawn as follows in the hope of providing a theoretical basis for the formulation of urban climate policies and urban development planning:

(1) Urbanization has significant impacts, but it was not as important as changes in natural/meteorological factors such as RAD, RHU, and so forth. There were differences in the explanatory power of the leading factors of precipitation change in Jing-Jin-Ji in different seasons. The variation of RAD was the leading factor of the change of precipitation in summer, explaining $21.3 \%$; the variation of RHU explained $16.9 \%$ of the spatial distribution of precipitation change. The dominant factors in winter were RAD, RHU, WIN, and AREA, for which the explanatory power reached $43.3 \%, 41.9 \%, 18.0 \%$, and $11.5 \%$, respectively. On an annual scale, the main factors influencing precipitation variation were changes in RHU, AOD, RAD, and WIN, for which the explanatory power was $33.2 \%, 30.0 \%$, $19.9 \%$, and $14.6 \%$, respectively.

(2) When considering the interaction, the impact of urbanization was very large, which could amplify the impact of man-made and natural/meteorological factors; the magnification and nonlinear relationship changed with different seasons. The interaction of RAD and NDVI was the most significant in summer. The interaction of UHI and RHU came next, with an explanatory power of $56.4 \%$. This indicates that a change in the underlying surface, together with the variation of UHI combined with RHU, can enhance the variation of precipitation in Jing-Jin-Ji. In the process of urbanization and its expansion, in order to prevent extreme drought and flooding, 
attention should be paid to the protection of vegetation. The interaction of RHU and AOD was most significant in winter, with an explanatory power of $76.6 \%$. The interaction of RAD and AOD came second, which indicated that air pollution plays an important role in precipitation change in Jing-Jin-Ji in winter. On an annual scale, the interaction of RAD and RHU was the most important factor of precipitation change in Jing-Jin-Ji; the interaction of RAD and AOD came next.

(3) Sensitivity factor. By comparing them with the natural factors, human factors, especially UHI and NLI, would greatly amplify the impact of other factors on precipitation change after interacting with other factors that have emerged as the most important and sensitive factors affecting urbanization. The effect of AOD on precipitation changes in summer and winter is greater than that of RHU, RAD, UHI, and so forth. This indicates that, in the process of urbanization, attention should be paid not only to the mitigation of UHI and the protection of green spaces, but also to the protection of the atmospheric environment.

Supplementary Materials: The following are available online at http://www.mdpi.com/2071-1050/12/18/7426/s1, Figure S1: The seasonal change rates for various factors affecting precipitation variation in Jing-Jin-Ji from 2000 to 2015). Figure S2: Analysis of precipitation Cold-Hot spots in Jing-Jin-Ji from 2000 to 2015. Table S1: Glossary of abbreviations used in this study. Table S2: Interaction $q$ value of influencing factors of precipitation changes in different cities from 2000 to 2015 in summer. Table S3: Interaction $q$ value of influencing factors of precipitation changes in different cities from 2000 to 2015 in winter. Table S4: Interaction $q$ value of influencing factors of precipitation changes in different cities from 2000 to 2015 in annual. Table S5: Cumulative change of $q$ value after a single factor interacts with other factors in summer. Table S6: Cumulative change of $q$ value after a single factor interacts with other factors in winter. Table S7: Cumulative change of $q$ value after a single factor interacts with other factors in annual.

Author Contributions: This manuscript is the result of the research of F.W. under the supervision of S.L. and the advising of Z.L., Z.H., Y.W., and H.W., and F.S. All authors designed the study, developed the methodology, discussed the results, and F.W. wrote the paper. All authors have read and agreed to the published version of the manuscript.

Funding: This research was funded by the Major Projects of the National Natural Science Foundation of China, grant number 41590843.

Acknowledgments: We thank the Major Projects of the National Natural Science Foundation of China (grant number 41590843) for its support. We are also grateful to the editor and the reviewers for their helpful comments.

Conflicts of Interest: The authors declare no conflict of interest.

\section{References}

1. Carvalho, D.; Martins, H.; Marta-Almeida, M.; Rocha, A.; Borrego, C. Urban resilience to future urban heatwaves under a climate change scenario: A case study for porto urban area (portugal). Urban Clim. 2017, 19, 1-27. [CrossRef]

2. Mendez-Lazaro, P.A.; Perez-Cardona, C.M.; Rodriguez, E.; Martinez, O.; Taboas, M.; Bocanegra, A.; Mendez-Tejeda, R. Climate change, heat, and mortality in the tropical urban area of San Juan, Puerto Rico. Int. J. Biometeorol. 2018, 62, 699-707. [CrossRef] [PubMed]

3. Oleson, K.W.; Anderson, G.B.; Jones, B.; McGinnis, S.A.; Sanderson, B. Avoided climate impacts of urban and rural heat and cold waves over the us using large climate model ensembles for rcp8.5 and rcp4.5. Clim. Chang. 2018, 146, 377-392. [CrossRef] [PubMed]

4. Polrolniczak, M.; Tomczyk, A.M.; Kolendowicz, L. Thermal conditions in the city of Poznan (Poland) during selected heat waves. Atmosphere 2018, 9, 11. [CrossRef]

5. Seino, N.; Aoyagi, T.; Tsuguti, H. Numerical simulation of urban impact on precipitation in Tokyo: How does urban temperature rise affect precipitation? Urban Clim. 2018, 23, 8-35. [CrossRef]

6. Zhao, N.; Jiao, Y.; Ma, T.; Zhao, M.; Fan, Z.; Yin, X.; Liu, Y.; Yue, T. Estimating the effect of urbanization on extreme climate events in the Beijing-Tianjin-Hebei region, China. Sci. Total Environ. 2019, 688, 1005-1015. [CrossRef] 
7. Kusaka, H.; Nishi, A.; Mizunari, M.; Yokoyama, H. Urban impacts on the spatiotemporal pattern of short-duration convective precipitation in a coastal city adjacent to a mountain range. Q. J. R. Meteorol. Soc. 2019, 145, 2237-2254. [CrossRef]

8. Zhao, L.; Lee, X.; Smith, R.B.; Oleson, K. Strong contributions of local background climate to urban heat islands. Nature 2014, 511, 216-219. [CrossRef]

9. Wai, K.M.; Wang, X.M.; Lin, T.H.; Wong, M.S.; Zeng, S.K.; He, N.; Ng, E.; Lau, K.; Wang, D.H. Observational evidence of a long-term increase in precipitation due to urbanization effects and its implications for sustainable urban living. Sci. Total Environ. 2017, 599, 647-654. [CrossRef]

10. Gu, Y.F.; Li, D. A modeling study of the sensitivity of urban heat islands to precipitation at climate scales. Urban Clim. 2018, 24, 982-993. [CrossRef]

11. Qiu, J. Urbanization contributed to beijing storms. Nature 2012, 10. [CrossRef]

12. Meng, W.G.; Yan, J.H.; Hu, H.B. Urban effects and summer thunderstorms in a tropical cyclone affected situation over guangzhou city. Sci. China Ser. D-Earth Sci. 2007, 50, 1867-1876. [CrossRef]

13. Yin, J.; Zhang, D.-L.; Luo, Y.; Ma, R. On the extreme rainfall event of 7 may 2017 over the coastal city of guangzhou. Part i: Impacts of urbanization and orography. Mon. Weather Rev. 2020, 148, 955-979. [CrossRef]

14. Wang, C.X.; Liu, L.Y. Empirical research on the impact to city climate caused by urbanization-A case of jinan city. In Progress in Environmental Protection and Processing of Resource; pts 1-4; Tang, X., Zhong, W., Zhuang, D., Li, C., Liu, Y., Eds.; Trans Tech Publications Ltd.: Stafa-Zurich, Switzerland, 2013; Volume 295-298, pp. 2669-2674.

15. Uchiyama, R.; Okochi, H.; Kamiya, J.; Asai, D.; Kaneko, C.; Ogata, H.; Katsumi, N. The impacts of "urban-induced heavy rains" on the distribution of deposition fluxes of inorganic acidic substances in the Tokyo metropolitan area in summer. Atmos. Res. 2018, 200, 109-116. [CrossRef]

16. Li, X.X.; Koh, T.Y.; Panda, J.; Norford, L.K. Impact of urbanization patterns on the local climate of a tropical city, Singapore: An ensemble study. J. Geophys. Res. Atmos. 2016, 121, 4386-4403. [CrossRef]

17. Zhang, W.; Villarini, G.; Vecchi, G.A.; Smith, J.A. Urbanization exacerbated the rainfall and flooding caused by hurricane harvey in houston. Nature 2018, 563, 384-388. [CrossRef]

18. Debbage, N.; Shepherd, J.M. Urban influences on the spatiotemporal characteristics of runoff and precipitation during the 2009 atlanta flood. J. Hydrometeorol. 2019, 20, 3-21. [CrossRef]

19. Paul, S.; Ghosh, S.; Mathew, M.; Devanand, A.; Karmakar, S.; Niyogi, D. Increased spatial variability and intensification of extreme monsoon rainfall due to urbanization. Sci. Rep. 2018, 8, 3918. [CrossRef]

20. Patel, P.; Ghosh, S.; Kaginalkar, A.; Islam, S.; Karmakar, S. Performance evaluation of wrf for extreme flood forecasts in a coastal urban environment. Atmos. Res. 2019, 223, 39-48. [CrossRef]

21. Lorenz, J.M.; Kronenberg, R.; Bernhofer, C.; Niyogi, D. Urban rainfall modification: Observational climatology over berlin, germany. J. Geophys. Res. Atmos. 2019, 124, 731-746. [CrossRef]

22. Changnon, S.A. Rainfall changes in summer caused by St-Louis. Science 1979, 205, 402-404. [CrossRef] [PubMed]

23. Baik, J.J.; Kim, Y.H.; Kim, J.J.; Han, J.Y. Effects of boundary-layer stability on urban heat island-induced circulation. Theor. Appl. Climatol. 2007, 89,73-81. [CrossRef]

24. Zhang, Y.; Pang, X.; Xia, J.; Shao, Q.; Yu, E.; Zhao, T.; She, D.; Sun, J.; Yu, J.; Pan, X.; et al. Regional patterns of extreme precipitation and urban signatures in metropolitan areas. J. Geophys. Res. Atmos. 2019, 124, 641-663. [CrossRef]

25. Daniels, E.E.; Lenderink, G.; Hutjes, R.W.A.; Holtslag, A.A.M. Observed urban effects on precipitation along the dutch west coast. Int. J. Climatol. 2016, 36, 2111-2119. [CrossRef]

26. Han, J.Y.; Baik, J.J.; Khain, A.P. A numerical study of urban aerosol impacts on clouds and precipitation. J. Atmos. Sci. 2012, 69, 504-520. [CrossRef]

27. Han, J.Y.; Baik, J.J.; Lee, H. Urban impacts on precipitation. Asia Pac. J. Atmos. Sci. 2014, 50, 17-30. [CrossRef]

28. Kusaka, H.; Nawata, K.; Suzuki-Parker, A.; Takane, Y.; Furuhashi, N. Mechanism of precipitation increase with urbanization in tokyo as revealed by ensemble climate simulations. J. Appl. Meteorol. Climatol. 2014, 53, 824-839. [CrossRef]

29. Dixon, P.G.; Mote, T.L. Patterns and causes of atlanta's urban heat island-initiated precipitation. J. Appl. Meteorol. 2003, 42, 1273-1284. [CrossRef]

30. Shepherd, J.M.; Burian, S.J. Detection of urban-induced rainfall anomalies in a major coastal city. Earth Interact. 2003, 7. [CrossRef] 
31. Pathirana, A.; Denekew, H.B.; Veerbeek, W.; Zevenbergen, C.; Banda, A.T. Impact of urban growth-driven landuse change on microclimate and extreme precipitation-A sensitivity study. Atmos. Res. 2014, 138, 59-72. [CrossRef]

32. Daniels, E.; Lenderink, G.; Hutjes, R.; Holtslag, A. Relative impacts of land use and climate change on summer precipitation in The Netherlands. Hydrol. Earth Syst. Sci. 2016, 20, 4129-4142. [CrossRef]

33. Wang, J.; Xu, C. Geodetector: Principle and prospective. Acta Geogr. Sin. 2017, 72, 116-134.

34. Liu, Y.; Dong, F. Corruption, economic development and haze pollution: Evidence from 139 global countries. Sustainability 2020, 12, 3523. [CrossRef]

35. Li, H.; Jia, P.; Fei, T. Associations between taste preferences and chronic diseases: A population-based exploratory study in China. Public Health Nutr. 2020. [CrossRef]

36. Hu, D.; Meng, Q.; Zhang, L.; Zhang, Y. Spatial quantitative analysis of the potential driving factors of land surface temperature in different "centers" of polycentric cities: A case study in Tianjin, China. Sci. Total Environ. 2020, 706, 135244. [CrossRef]

37. Hu, M.; Lin, H.; Wang, J.; Xu, C.; Tatem, A.J.; Meng, B.; Zhang, X.; Liu, Y.; Wang, P.; Wu, G.; et al. The risk of covid-19 transmission in train passengers: An epidemiological and modelling study. Clin. Infect. Dis. 2020. [CrossRef]

38. Cheng, C.; Liu, Y.; Liu, Y.; Yang, R.; Hong, Y.; Lu, Y.; Pan, J.; Chen, Y. Cropland use sustainability in Cheng-yu urban agglomeration, China: Evaluation framework, driving factors and development paths. J. Clean. Prod. 2020, 256, 120692. [CrossRef]

39. Wu, K.; Wang, Y.; Ye, Y.; Zhang, H.; Huang, G. Relationship between the built environment and the location choice of high-tech firms: Evidence from the Pearl River delta. Sustainability 2019, 11, 3689. [CrossRef]

40. Wang, J.; Li, X.; Christakos, G.; Liao, Y.; Zhang, T.; Gu, X.; Zheng, X. Geographical detectors-based health risk assessment and its application in the neural tube defects study of the Heshun region, China. Taylor Francis 2010, 24, 107-127. [CrossRef]

41. Liang, Z.; Wu, S.Y.; Wang, Y.Y.; Wei, F.L.; Huang, J.; Shen, J.S.; Li, S.C. The relationship between urban form and heat island intensity along the urban development gradients. Sci. Total Environ. 2019, 708, 135011. [CrossRef]

42. Huang, J.L.; Wang, R.S.; Li, F.; Yang, W.R.; Zhou, C.B.; Jin, J.S.; Shi, Y. Simulation of thermal effects due to different amounts of urban vegetation within the built-up area of Beijing, China. Int. J. Sustain. Dev. World Ecol. 2009, 16, 67-76. [CrossRef]

43. Kamal, S.; Huang, H.P.; Myint, S.W. The influence of urbanization on the climate of the Las Vegas metropolitan area: A numerical study. J. Appl. Meteorol. Climatol. 2015, 54, 2157-2177. [CrossRef]

44. Yue, W.; Xu, J.; Tan, W.; Xu, L. The relationship between land surface temperature and ndvi with remote sensing: Application to Shanghai landsat 7 etm+ data. Int. J. Remote Sens. 2007, 28, 3205-3226. [CrossRef]

45. Zhang, C.L.; Chen, F.; Miao, S.G.; Li, Q.C.; Xia, X.A.; Xuan, C.Y. Impacts of urban expansion and future green planting on summer precipitation in the Beijing metropolitan area. J. Geophys. Res. Atmos. 2009, 114, D02116. [CrossRef]

46. Li, X.; Zhou, Y.; Zhao, M.; Zhao, X. A harmonized global nighttime light dataset 1992-2018. Sci. Data $2020,7$. [CrossRef]

47. Kotharkar, R.; Surawar, M. Land use, land cover, and population density impact on the formation of canopy urban heat islands through traverse survey in the Nagpur urban area, India. J. Urban Plan. Dev. 2016, 142, 13. [CrossRef]

48. Wang, J.L.; Zhang, R.H.; Wang, Y.C. Areal differences in diurnal variations in summer precipitation over Beijing metropolitan region. Theor. Appl. Climatol. 2012, 110, 395-408. [CrossRef]

49. Jiang, Z.; Li, Y. Impact of urbanization in different regions of eastern China on precipitation and its uncertainty. J. Trop. Meteorol. 2014, 30, 601-611.

50. Wang, J.; Feng, J.M.; Yan, Z.W. Impact of extensive urbanization on summertime rainfall in the Beijing region and the role of local precipitation recycling. J. Geophys. Res. Atmos. 2018, 123, 3323-3340. [CrossRef]

51. Yu, M.; Miao, S.G.; Zhang, H.B. Uncertainties in the impact of urbanization on heavy rainfall: Case study of a rainfall event in Beijing on 7 August 2015. J. Geophys. Res. Atmos. 2018, 123, 6005-6021. [CrossRef]

52. Holst, C.C.; Chan, J.C.L.; Tam, C.Y. Sensitivity of precipitation statistics to urban growth in a subtropical coastal megacity cluster. J. Environ. Sci. 2017, 59, 6-12. [CrossRef] [PubMed] 
53. Shepherd, J.M.; Carter, M.; Manyin, M.; Messen, D.; Burian, S. The impact of urbanization on current and future coastal precipitation: A case study for houston. Environ. Plan. B Plan. Des. 2010, 37, 284-304. [CrossRef]

54. Oliveros, J.M.; Vallar, E.A.; Galvez, M.C.D. Investigating the effect of urbanization on weather using the weather research and forecasting (wrf) model: A case of metro Manila, Philippines. Environments 2019, 6, 10. [CrossRef]

55. Ooi, M.C.G.; Chan, A.; Ashfold, M.J.; Morris, K.I.; Oozeer, M.Y.; Salleh, S.A. Numerical study on effect of urban heating on local climate during calm inter-monsoon period in greater Kuala Lumpur, Malaysia. Urban Clim. 2017, 20, 228-250. [CrossRef]

56. Souma, K.; Tanaka, K.; Suetsugi, T.; Sunada, K.; Tsuboki, K.; Shinoda, T.; Wang, Y.; Sakakibara, A.; Hasegawa, K.; Moteki, Q.; et al. A comparison between the effects of artificial land cover and anthropogenic heat on a localized heavy rain event in 2008 in Zoshigaya, Tokyo, Japan. J. Geophys. Res. Atmos. 2013, 118, 11600-11610. [CrossRef]

(C) 2020 by the authors. Licensee MDPI, Basel, Switzerland. This article is an open access article distributed under the terms and conditions of the Creative Commons Attribution (CC BY) license (http://creativecommons.org/licenses/by/4.0/). 